\title{
Varied nanostructures from a single multifunctional molecular material $\uparrow t$
}

\author{
David Canevet, ${ }^{a}$ Ángel Pérez del Pino, ${ }^{b}$ David B. Amabilino*b and Marc Sallé ${ }^{* a}$
}

\author{
Received 16th July 2010, Accepted 14th September 2010 \\ DOI: 10.1039/c0jm02302g
}

\begin{abstract}
The control of the morphology of nanostructures formed from a single component molecular material incorporating electron accepting and donating moieties is shown, from both solution and gel states. The compound comprises one tetrathiafulvalene (TTF) and two pyrene units which act as the $\pi$-electron rich and deficient units, respectively, and which are united by amide-containing linkers whose additional role is to aide aggregation by hydrogen bonding. This role was demonstrated by IR and NMR spectroscopy. The gels were deposited onto surfaces and the solvent allowed to evaporate, leaving films formed by meshes of fibres with different morphologies in accord with the different solvents used to form the materials. Doping of these xerogels with iodine vapour afforded conducting films whose characteristics were probed with current sensing atomic force microscopy (CS-AFM), providing current maps and $I-V$ curves which show how dramatically the processing solvent can influence the electronic properties of these xerogel-derived materials.
\end{abstract}

\section{Introduction}

The controlled self-assembly of functional nanostructures from molecular components is an area of great contemporary interest. ${ }^{1}$ This attention was instigated by the scientific challenge of controlling the self-assembly of these systems ${ }^{2}$ as well as by the hope that they will find application in functional organic molecule-based nanosystems made from bottom-up strategies. ${ }^{3}$ The use of supramolecular structure-directing moieties - such as hydrogen bonding units - coupled with $\pi$-functional units and solubilising groups to afford processability can lead to systems which display the kind of characteristics which are useful in nanoscience. ${ }^{4}$ In particular, the deposition of molecules onto surfaces from solution ${ }^{1 j, 5}$ and from the gel state ${ }^{6}$ are interesting because nanometre wide fibres can be generated which act as wires for charge transport. ${ }^{7}$ Multifunctional systems which incorporate more than one active $\pi$ unit are particularly appealing in that multiple signals might operate at the same time ${ }^{8}$ and the different groups can give interesting supramolecular assemblies from the purely structural point of view. ${ }^{9}$

In this work, we report the synthesis, nanostructure-forming capability, and electronic properties of molecule 1. This compound was targeted because it contains the tetrathiafulvalene (TTF) moiety, which is of proven utility in electronic materials as well as for sensing of different chemical species, ${ }^{10}$ as well as the pyrene unit which is an established fluorophore ${ }^{11}$ and electron accepting unit. ${ }^{12}$ Gels of these components $\left(\mathrm{TTF}^{13}\right.$ and pyrene ${ }^{14}$ ) have been described, but as far as we are aware their combination in a gelating derivative such as $\mathbf{1}$ is not known. However, it is

${ }^{a}$ Université d'Angers, Laboratoire MOLTECH-Anjou, UMR CNRS 6200 , 2 boulevard Lavoisier, Angers, France. E-mail: marc.salle@univ-angers.fr; Fax: +33 241735405; Tel: +33241735439

${ }^{b}$ Institut de Ciència de Materials de Barcelona (CSIC), Campus Universitari de Bellaterra, 08193 Cerdanyola del Vallès, Catalonia, Spain.E-mail: amabilino@icmab.es

$\dagger$ This paper is part of a Journal of Materials Chemistry themed issue in celebration of the 70th birthday of Professor Fred Wudl.

\$ Electronic supplementary information (ESI) available: further experimental details. See DOI: 10.1039/c0jm02302g a combination which is potentially very interesting, given the reversible redox chemistry of the TTF unit and the inherent properties of the pyrene moiety (such as its photophysics and $\pi-\pi$ stacking ability). The results presented here indicate that this hope is founded.

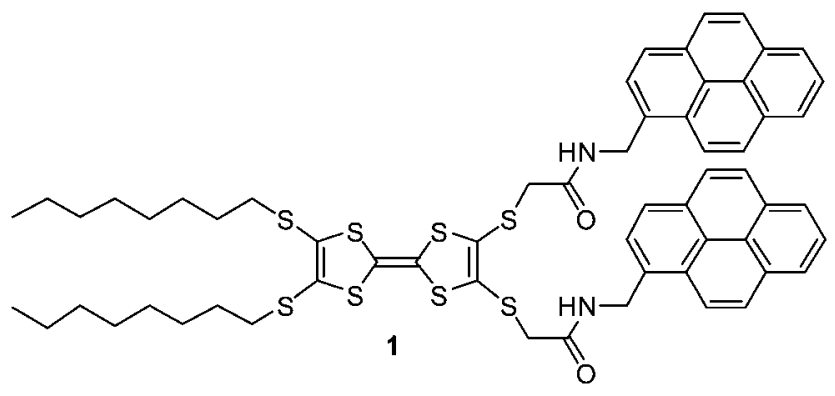

\section{Results and discussion}

\section{Synthesis and characterisation}

Compound 1 was prepared by the route shown in Scheme 1. Starting from compound $\mathbf{2}$ (see ESI $\$$ ), treatment with caesium hydroxide to produce the intermediate thiolate $\mathbf{3}$ and reaction in dimethylformamide with the known pyrene derivative $4^{15}$ afforded the desired compound in $75 \%$ yield as an analytically pure orange precipitate.

Compound 1 was characterised by all the usual spectroscopic techniques which confirmed its identity. Electrochemical study (CV) of compound 1 showed four oxidation waves (Fig. 1a). The first three redox processes are pseudoreversible as illustrated by the deconvoluted CV (Fig. 1b), whereas the last one is irreversible. Therefore, as usually observed with highly donating TTF derivatives, compound $\mathbf{1}$ is first successively oxidized according to two one electron processes to the TTF radical-cation $\left(\mathrm{E}_{1 / 2}^{1}=\right.$ $0.01 \mathrm{~V}$ vs. $\left.\mathrm{Fc}^{+} / \mathrm{Fc}\right)$ and the dication state $\left(\mathrm{E}_{1 / 2}^{2}=0.40 \mathrm{~V} v s . \mathrm{Fc}^{+} /\right.$ $\mathrm{Fc})$. The most anodic signals $\left(\mathrm{E}^{3}{ }_{1 / 2}=0.76 \mathrm{~V}\right.$ and $\mathrm{E}_{\mathrm{p}}^{4}=1.04 \mathrm{~V} v s$. $\left.\mathrm{Fc}^{+} / \mathrm{Fc}\right)$ are assignable to one-electron oxidations of both pyrene 


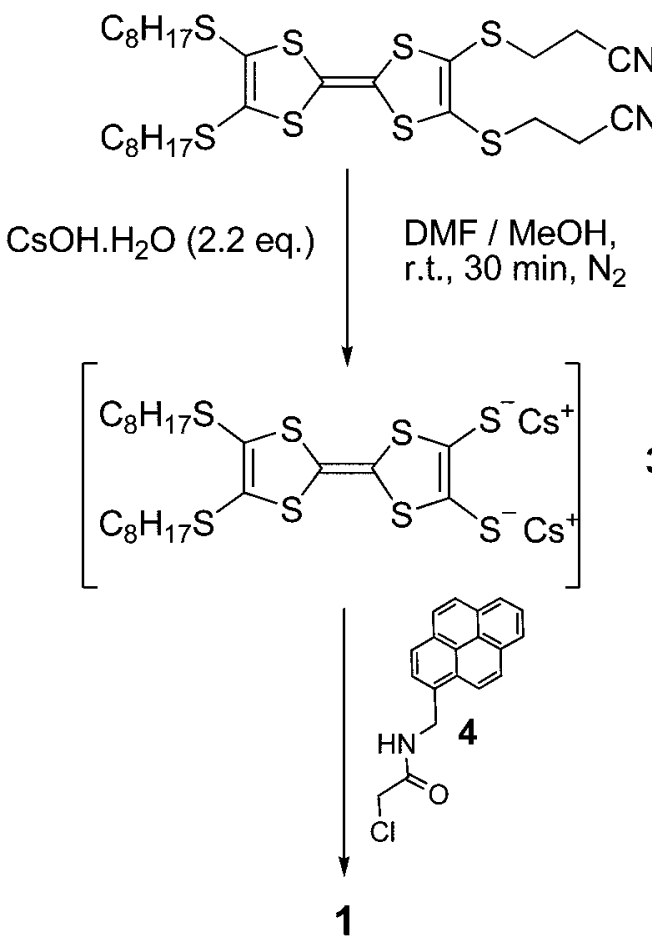

Scheme 1 Synthesis of target 1

units to their radical cation state. The fact that both pyrene units are not oxidized at the same potential is probably due to intramolecular interaction which takes place to stabilize the mixed-valence $(\mathrm{Pyr}-\mathrm{Pyr})^{+} \operatorname{dimer}^{16}$ intermediate $\left(\mathrm{E}_{3}\right)$, whereas oxidation of the last pyrenyl unit needs a higher potential, and is irreversible as usually observed with monopyrenyl derivatives. ${ }^{12 d, 17}$

\section{Phase behaviour in solvents}

The solubility of molecular systems in organic solvents is of utmost importance in their processing, and therefore a study of the phase behaviour of $\mathbf{1}$ in solvents with very different properties (in terms of polarity, hydrogen bonding capability, etc.) was assayed. The results are collected in Table 1 .

Compound 1 proved to be a good gelator in five of the solvents used in this study, namely chlorobenzene (CB), 1,2dichlorobenzene (ODCB), dichloromethane, chloroform, and tetrahydrofuran (THF) (Fig. 2) from which low critical gel concentration (CGC) values are observed. It is evident that the formation of gels is best in chlorinated solvents. The observation of a gel in THF and a precipitate in dioxane shows the difference in the solvents in terms of their behaviour towards solvates of the type described here. The compound is not sufficiently soluble in hydrocarbon solvents to be able to form a gel. Nonetheless, the gels formed provide the opportunity to study the effect of the media on the eventual properties of the doped xerogels, in a variety of solvents far greater than a previous case. ${ }^{18}$ In addition, slight changes in organogelator structure can have important effects on the structure of the fibres that result from their self-assembly. ${ }^{19}$
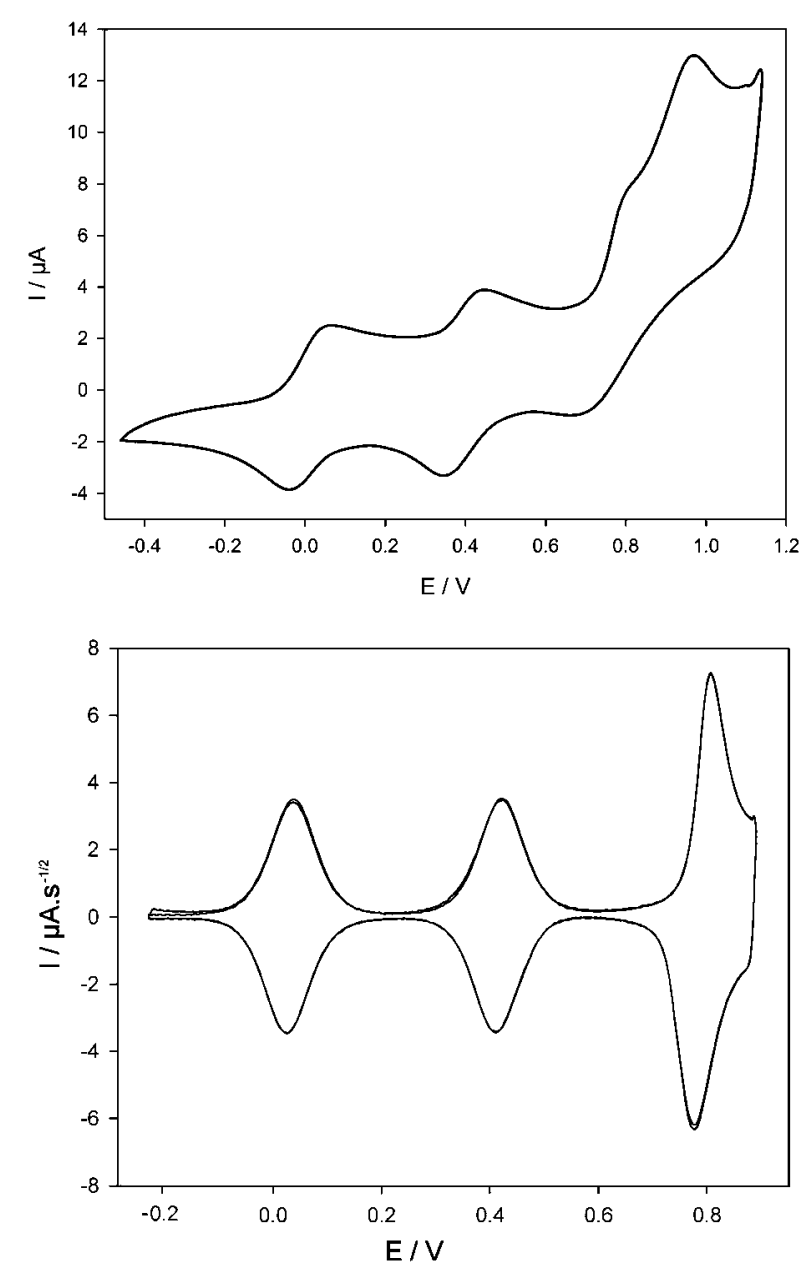

Fig. 1 Cyclic voltammogram (top) and the deconvoluted version (bottom) of 1 ([1] $=5 \times 10^{-4} \mathrm{M}, \mathrm{CH}_{2} \mathrm{Cl}_{2}, \mathrm{TBAPF}_{6}(0.1 \mathrm{M})$, E vs. ferrocinium/ferrocene, $\left.100 \mathrm{mV} \mathrm{s}^{-1}\right)$.

The non-covalent interactions taking place between the molecules of $\mathbf{1}$ are principally hydrogen bonding between the secondary amide residues, as revealed in the infrared (IR) spectra of the xerogels (Fig. 3). The spectra of the xerogels formed from different solvents all show the same characteristic band at approximately $3290 \mathrm{~cm}^{-1}$, arising from the hydrogen bonded $\mathrm{N}-\mathrm{H}$ groups. In addition, the corresponding $\mathrm{C}=\mathrm{O}$ stretching and $\mathrm{N}-\mathrm{H}$ bending bands are observed at 1636 and $1549 \mathrm{~cm}^{-1}$, respectively. Furthermore, the van der Waals interactions between the alkyl chains of the molecules and interactions between aromatic residues are also likely to influence the behaviour. The NMR spectra of $\mathbf{1}$ at different concentrations (from lower to higher concentrations respectively than the CGC of 1 in chloroform $\left(\mathrm{CGC}=6 \mathrm{mg} \mathrm{L}^{-1}\right)$ ) in deuterated chloroform (Fig. 4) show a clear shift to high field of the significant proton resonances from the pyrene unit, whereas the amide $\mathrm{N}-\mathrm{H}$ signal is shifted to lower fields upon increasing the concentration. Such behavior illustrates the progressive installation of intermolecular interactions upon the gel formation process. Remarkably, the shift observed for $\delta(\mathrm{NH})$ is more important in the case of lower concentrations $\left([\mathbf{1}]=1\right.$ to $\left.5 \mathrm{mg} \mathrm{mL}^{-1}\right)$, than for higher concentrations. This observation is correlated with a progressive increasing of the hydrogen bond contribution for 
Table 1 Test for solubility and gel formation for compound $\mathbf{1}-\mathrm{P}$ is for precipitate, $\mathrm{S}$ for solution, $\mathrm{G}$ for gel. In the case of the gels, the stated mass is the minimum required for gel formation

\begin{tabular}{llll}
\hline Solvent & $\begin{array}{l}\text { State in } \\
\text { hot solvent }\end{array}$ & $\begin{array}{l}\text { State at } \\
\text { ambient } \\
\text { temperature }\end{array}$ & $\begin{array}{l}\text { Amount } \\
\text { of } \mathbf{1 ~ i n ~} \\
\mathrm{mg} \mathrm{mL}^{-1}\end{array}$ \\
\hline Cyclohexane & $\mathrm{P}$ & $\mathrm{P}$ & 1 \\
Hexane & $\mathrm{P}$ & $\mathrm{P}$ & 1 \\
Limonene & $\mathrm{P}$ & $\mathrm{P}$ & 1 \\
Toluene & $\mathrm{S}$ & $\mathrm{P}$ & 1 \\
Chlorobenzene & $\mathrm{S}$ & $\mathrm{G}$ & 6 \\
1,2-Dichlorobenzene & $\mathrm{S}$ & $\mathrm{G}$ & 5 \\
Dichloromethane & $\mathrm{S}$ & $\mathrm{G}$ & 7 \\
Chloroform & $\mathrm{S}$ & $\mathrm{G}$ & 8 \\
1,2-Dichloroethane & $\mathrm{S}$ & $\mathrm{P}$ & 3 \\
Dioxane & $\mathrm{S}$ & $\mathrm{P}$ & 1 \\
Ethyl acetate & $\mathrm{S}$ & $\mathrm{P}$ & 1 \\
Acetone & $\mathrm{S}$ & $\mathrm{P}$ & 1 \\
Tetrahydrofuran & $\mathrm{S}$ & $\mathrm{G}$ & 12 \\
Methanol & $\mathrm{P}$ & $\mathrm{P}$ & 1 \\
Ethanol & $\mathrm{P}$ & $\mathrm{P}$ & 1 \\
Isopropanol & $\mathrm{P}$ & $\mathrm{P}$ & 1 \\
Acetonitrile & $\mathrm{P}$ & $\mathrm{P}$ & 1 \\
Dimethylformamide & $\mathrm{S}$ & $\mathrm{P}$ & 20 \\
Dimethylsulfoxide & $\mathrm{S}$ & $\mathrm{P}$ & 4 \\
\hline
\end{tabular}

low concentrations in compound $\mathbf{1}$, untill the gel state is reached (CGC), for which saturation of the H-bond network may be expected. The effect of solvent on gelating ability of molecules has been established for molecules which are able to immobilise a wide range of matrices. ${ }^{20}$ In the present case, the molecule gels in chlorinated solvents and THF, and is insoluble in other solvents. This characteristic is presumably a result of the insolubility caused by either hydrogen bonding and/or $\pi-\pi$ stacking, depending on the solvent in question. Explaining the influence of solvent on the morphology type of the xerogel is presently beyond the capacity of knowledge in organic materials of this kind. The very subtle changes in fibre structure between the chlorinated solvents, for example, are presumably a result of complex interactions of the component fibres and the solvent that is immobilised. The aromatic solvents would be expected to interact well with the pyrene part of the molecule, and this may be the reason for the well defined long thin fibres formed in $\mathrm{CB}$ and ODCB.

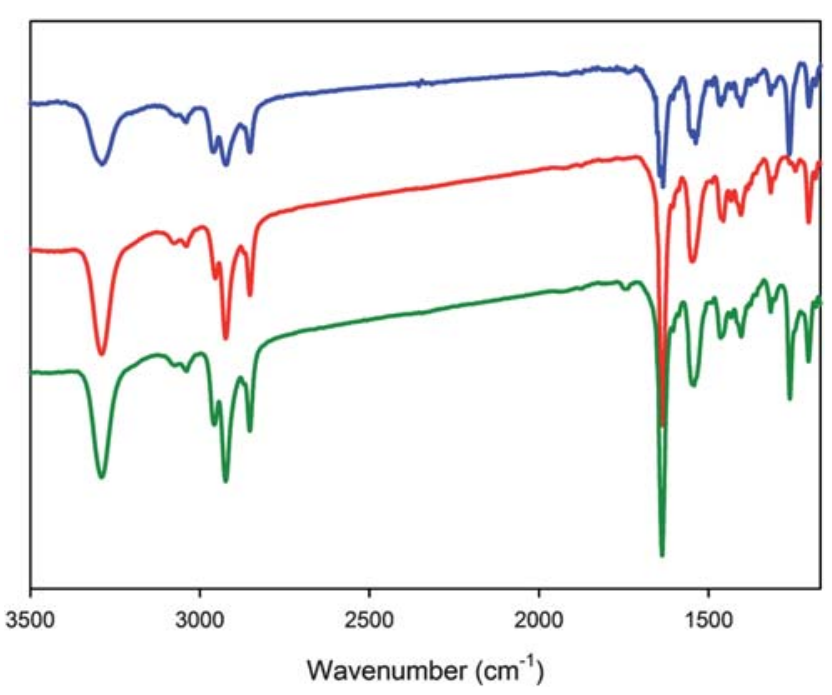

Fig. 3 Representative IR absorption spectra of the xerogels of $\mathbf{1}$ formed from $\mathrm{CB}$ (green), ODCB (red) and $\mathrm{CHCl}_{3}$ (blue).

\section{Deposition of 1 on surfaces from solution}

Compound $\mathbf{1}$ has a clear tendency to aggregate in solutions of chlorinated solvents below the critical gel concentration ( $c f$. NMR study), and also to form fibrous precipitates from the other solvents assayed in the gelation tests. Therefore, we studied the type of aggregates formed by precipitation on surfaces by drop casting from different media. Solvent has been shown before to have an important role in the formation of nanostructures by organic compounds, ${ }^{21}$ and the same is true here.

A hot acetone solution of $\mathbf{1}$ cast onto glass forms an interesting morphology in which lines of a complex mesh of fibres are generated at the surface (Fig. 5). These fibres are partially aligned upon evaporation of the solvent, as shown in the top photograph and the SEM of Fig. 5, although there are areas of non-aligned material. This kind of alignment in a much more regular form has been seen in a larger $C_{3}$ symmetrical molecule comprising three porphyrin units when cast from chloroform onto mica. ${ }^{22}$ In the present case, the fibres are 5 microns wide, and the SEM measurements indicate that they are quite porous.

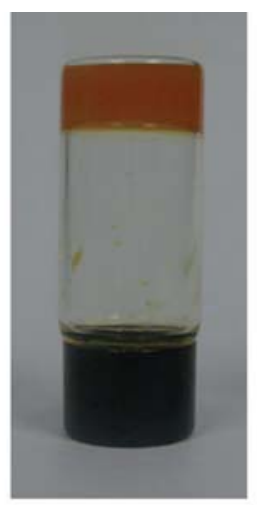

THF

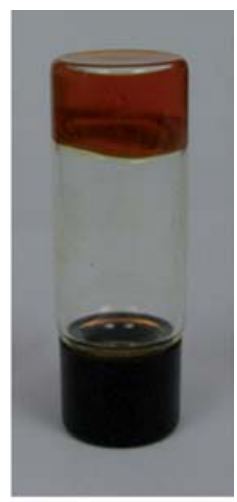

$\mathrm{CHCl}_{3}$

Fig. 2 Organogels formed by 1 in different solvents. 


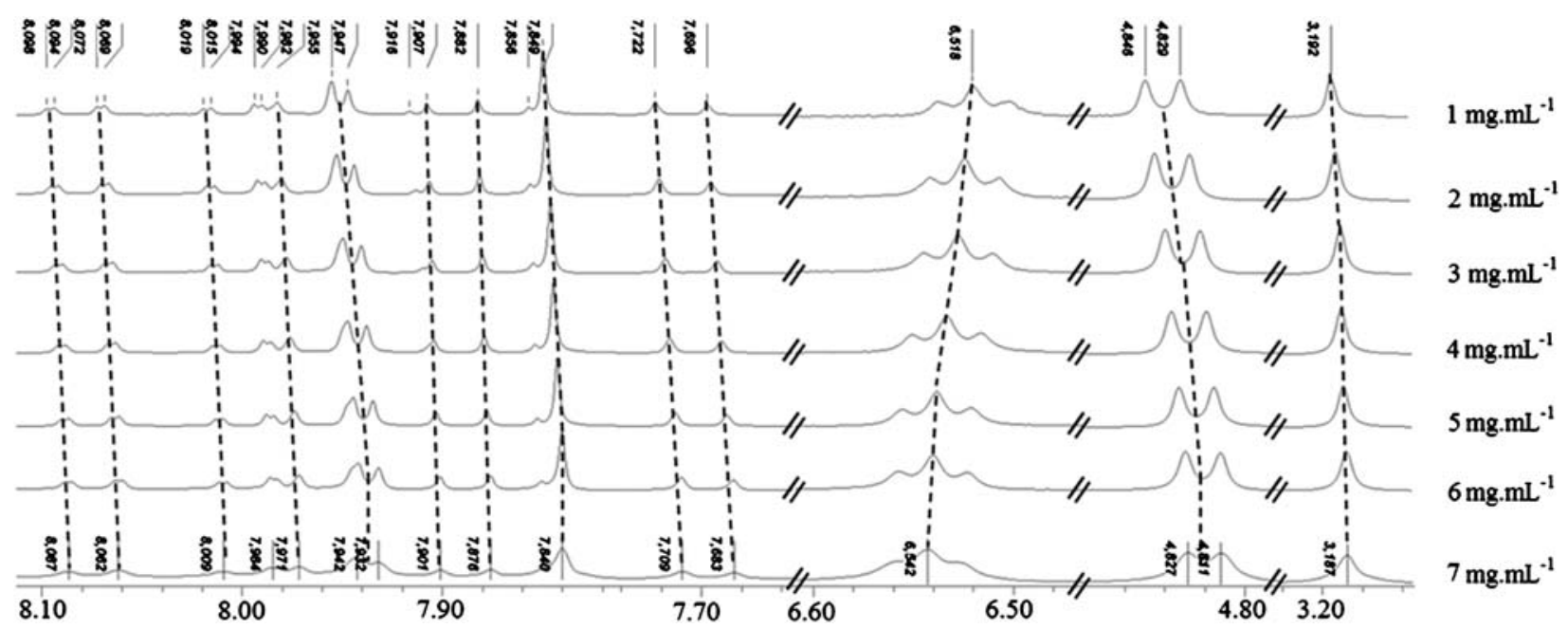

Fig. 4 Low field region of the ${ }^{1} \mathrm{H}$ NMR spectra of $\mathbf{1}$ in $\mathrm{CDCl}_{3}$ at different concentrations.

The walls of this porous structure are less than $50 \mathrm{~nm}$ thick (Fig. 6), as are the smaller fibres that emanate from the larger parent structure. Remarkably, there seems to be a degree of structural order in the material, as shown by the polarised optical micrograph shown in Fig. 5.

From both ethyl acetate and toluene, in which the compound is only soluble when the suspension is warmed, a random globular-like morphology is generated by $\mathbf{1}$ upon deposition onto glass slides (images not shown). Although the objects do polarise transmitted light, which indicates at least some short range order in the component fibres, there is no evident long-range structure in the systems, which are only slightly different to each other in appearance in the optical microscope and SEM images. A very different situation arises from dioxane. In this case a dense mesh of fibres based around dense islands of the structure is generated (Fig. 7). Again, material with short range order is prepared, as light is polarised when passing through it, and fibres link the clustered nodes (see SEM image in Fig. 7). In this case the smallest fibres observable in the SEM measurement are approximately $20 \mathrm{~nm}$ wide, and are interconnected over shortscale lengths. No individual fibres are observed over a micron long. Given the similarities with typical xerogel morphology, attempts were performed at higher concentrations $\left(8 \mathrm{mg} \mathrm{mL}^{-1}\right)$ but resulted in precipitation.

\section{Xerogels of 1}

Drying of the gels formed by $\mathbf{1}$ in the different solvents which it immobilises afforded orange solids which were subject to both spectroscopic and morphological analysis. The IR spectra of the gels reveal that essentially the same network of noncovalent interactions must be operational in all the solvents, as the peaks of all the functional groups appear in the same position regardless of the solvent used for processing (vide supra), indicating that at least at the first degree of organisation the assemblies are similar. We interpret that this first level contains hydrogen bonded fibres a single molecule wide.

Interestingly, the morphology of the xerogels is dramatically different. The samples were studied by transmission electron microscopy (TEM, Fig. 8) by drop casting a hot solution of $\mathbf{1}$ onto a holey carbon grid and the measurements were made with no staining of the organic material in order to ensure an authentic image. The xerogels from both CB and ODCB show well defined fibres with widths of a few tens of nanometres and lengths over several microns and which intertwine with each other. However, it is noteworthy that the xerogels from ODCB have far less crossing points between the fibres than the xerogels formed by CB. It is the contacts between fibres that are important for bulk conducting properties of these gels, and it is
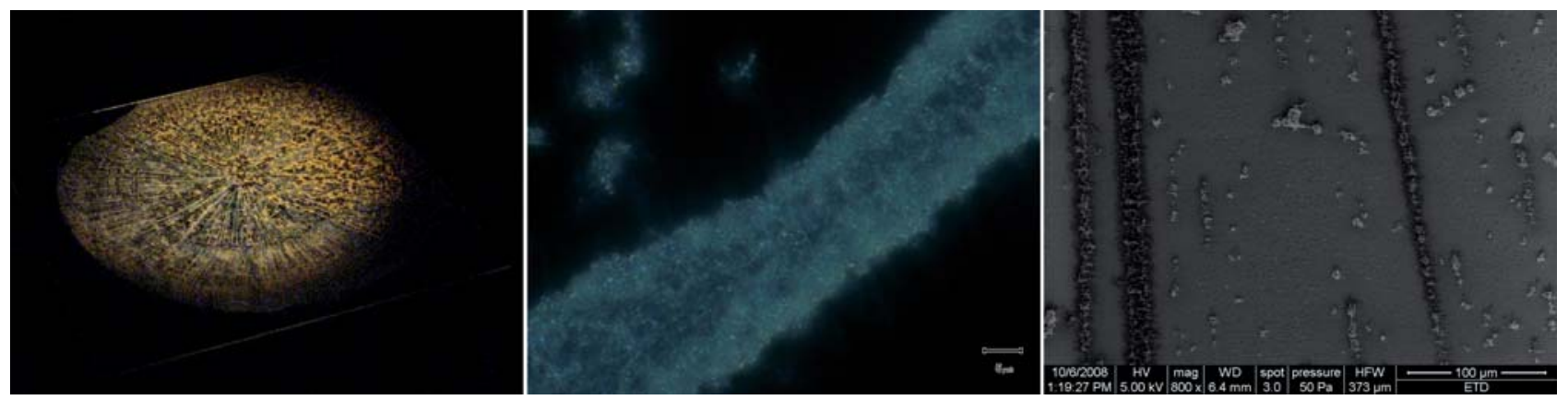

Fig. 5 Photograph of the drop formed upon solvent evaporation (left), polarising optical micrograph (centre) and SEM image (right) of the fibre mesh formed by $\mathbf{1}$ upon precipitation from a hot acetone solution onto glass. 


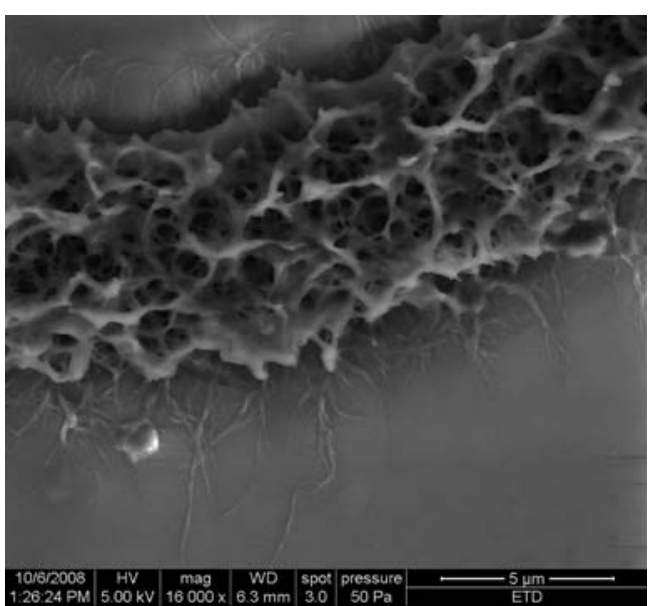

Fig. 6 SEM image of the porous fibre formed by 1 upon precipitation of a hot acetone solution onto glass.

important to keep this point in mind when discussing these characteristics (vide infra). The xerogels formed from chloroform shows a dense mesh of fibres with a range of fibre widths from a few tens to a hundred nanometres. The xerogels formed from THF are completely different to the other gels, with ribbons formed in the sample. These tape-like objects are approximately $50 \mathrm{~nm}$ wide and are very thin (sub-10 nm, see especially the top left hand part of the TEM image in Fig. 8).

The xerogels were also investigated using atomic force microscopy (AFM) and SEM on different substrates, and essentially the same morphologies were observed. As an example, the AFM image of the xerogels from ODCB is shown in Fig. 9. The fibres are approximately $20 \mathrm{~nm}$ in height, corresponding well with the size of the aggregates seen in the TEM images.

\section{Conducting materials derived from doped xerogels of 1}

The xerogels of $\mathbf{1}$ from the different solvents were prepared on surfaces by casting warm solutions of the compound above the critical gel concentration, and then the solvent was evaporated at room temperature using, if necessary, a vacuum pump. The xerogels were then subject to doping in a chamber with iodine vapour for five minutes. The oxidation of the TTF unit was immediately evident from the dark colour of the films, and the presence of a mixed valence state was proven by spectroscopy. Recording the FT-IR-near infrared (NIR) spectrum of a sample of the xerogel on a $\mathrm{KBr}$ disc prior to and after doping shows the presence of a broad and very intense charge transfer band centred on $3000 \mathrm{~cm}^{-1}$, as shown for example in the case of the xerogel prepared from an ODCB solution (Fig. 10; see also ESIt). Another characteristic, thinner, band of the doping process appears at $1230 \mathrm{~cm}^{-1} \cdot{ }^{23}$ Remarkably, the IR spectra does not evolve significantly with time as shown in Fig. 10, which illustrates the stability of the system in the doped form. Moreover, IR bands associated with the amide groups $(3289,1636$ and $1549 \mathrm{~cm}^{-1}$ ) do not change upon iodine doping, which indicates that the intermolecular hydrogen bond network is not modified, and that no structural reorganization involving these interactions occurs within the material upon oxidation.
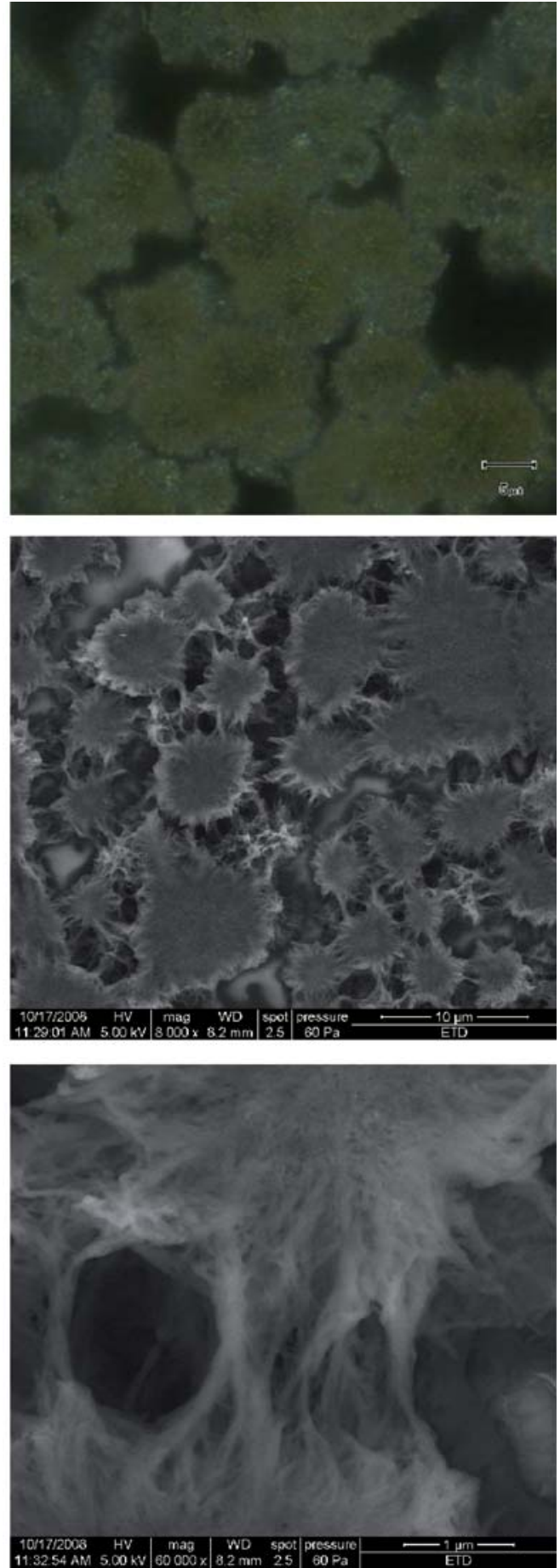

Fig. 7 Polarising optical micrograph (top) and SEM images (middle and bottom) of the island-based fibre mesh formed by $\mathbf{1}$ upon precipitation from a hot dioxane solution onto glass.

The electron spin resonance (ESR) signals of the materials, on the other hand, are quite different, although all show a relatively narrow peak-to-peak linewidth (Table 2). These values should be compared to the $14 \mathrm{G}$ or $20 \mathrm{G}$ values for samples of another bisamide TTF derivative, ${ }^{18}$ and imply that the dimensionality of the fibres formed by $\mathbf{1}$ is lower than in that case. Although the variation in the linewidth is limited, it correlates approximately with the observed morphologies of the xerogels: the chloroform 

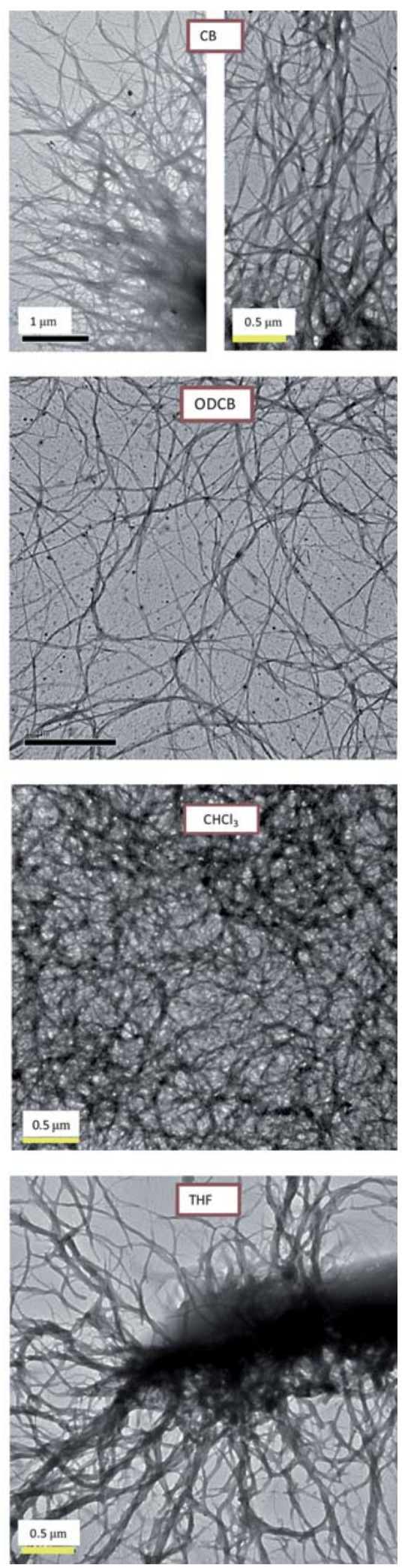

Fig. 8 TEM images of the xerogels formed by 1 in different solvents.

sample seems to have more clumped fibres and has the larger linewidth indicating greater dimensionality. Nevertheless, such an observation is not sufficient to correlate linewidth with the conductivity of the material (see below, especially the case of the
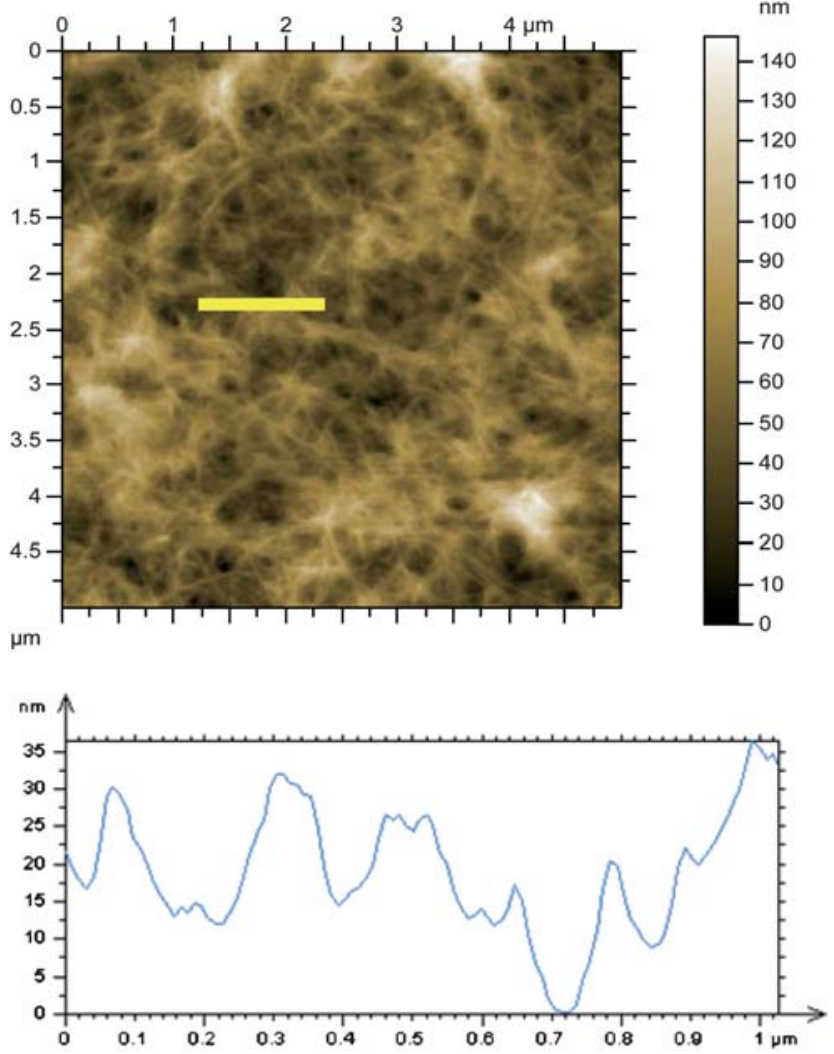

Fig. 9 AFM image and profile corresponding to the line in the image for the xerogel of 1 cast on graphite.

xerogel prepared from $\mathrm{CB}$ ), presumably because of the different parameters which have to be taken into account such as interfibre connectivity.

The electrical properties of the doped xerogels were studied by current sensing atomic force microscopy (CS-AFM). The samples were prepared on highly oriented pyrolytic graphite to ensure an easy contact from the bottom of the sample. Therefore, the current to and from the conducting tip of the AFM passes through the whole material to the graphite which is connected to the wire which completes the circuit. In the measurements, the current is measured while raster scanning while maintaining the tip in contact with the sample at a fixed potential, giving a current map and the topography of the sample which is measured simultaneously. As an example, the topographic image and current map of the doped xerogels derived from the THF are shown in Fig. 11. Both images show a random network of fibres, and the current map reveals that the current is passed relatively uniformly through the material. This result indicates clearly that the current passes through the fibres and must pass between fibres in order to travel through the material to the counterelectrode. The current maps of the gels derived from the other solvents also show a fibrilar morphology and relatively uniform transport of charge.

The histograms of the current in these maps (Fig. 12) are informative, as they show the distribution and order of magnitude of conductance. The materials prepared via the chlorobenzene and chloroform gels are the most conducting, and this observation would correlate with the excellent interlinking of the 

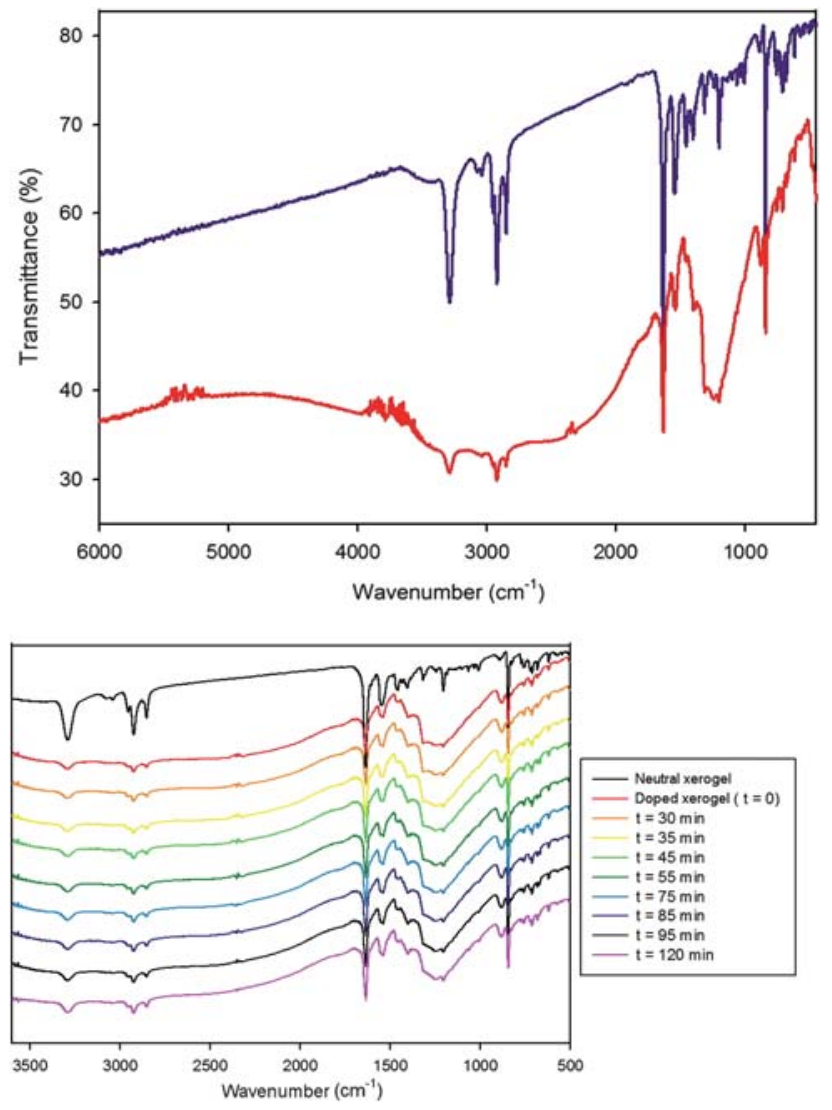

Fig. 10 Top: IR absorption spectra of the xerogel of $\mathbf{1}$ formed from ODCB, before (upper curve), and after $\mathrm{I}_{2}$ doping (lower curve); bottom: at different times after doping.

Table 2 Peak-to-peak line widths of the ESR spectra of the doped xerogels of 1

\begin{tabular}{lll}
\hline Solvent & $\mathrm{g}$ & $\Delta \mathrm{Hpp} / \mathrm{G}$ \\
\hline Chlorobenzene & 2.0072 & $8.7 \mathrm{G}$ \\
1,2-Dichlorobenzene & 2.0072 & $10.0 \mathrm{G}$ \\
Tetrahydrofuran & 2.0071 & $10.2 \mathrm{G}$ \\
Chloroform & 2.0070 & $12.7 \mathrm{G}$ \\
\hline
\end{tabular}

fibres seen in the TEM images of these materials. All of the materials show a relatively uniform conduction, bearing in mind that the histograms were recorded in different areas on the samples. Therefore, while local fluctuations are seen in the current maps, the difference in resistance between areas is not big.

The I-V spectroscopy curves (Fig. 13) corroborate the information in the histograms. The doped xerogels formed from chloroform and chlorobenzene show high and uniform conductivity. These samples are those which have the most uniformly connected fibres in the microscopy images of the undoped materials, and the connectivity between fibres is absolutely essential in the present measurement in which charge is passed from tip to surface through the material. The ODCB sample has long uniform fibres, but few crossing points, and this is reflected in a poor conductivity for the sample. The spectroscopy curves are generally rather flat with current at the level of picoamps even
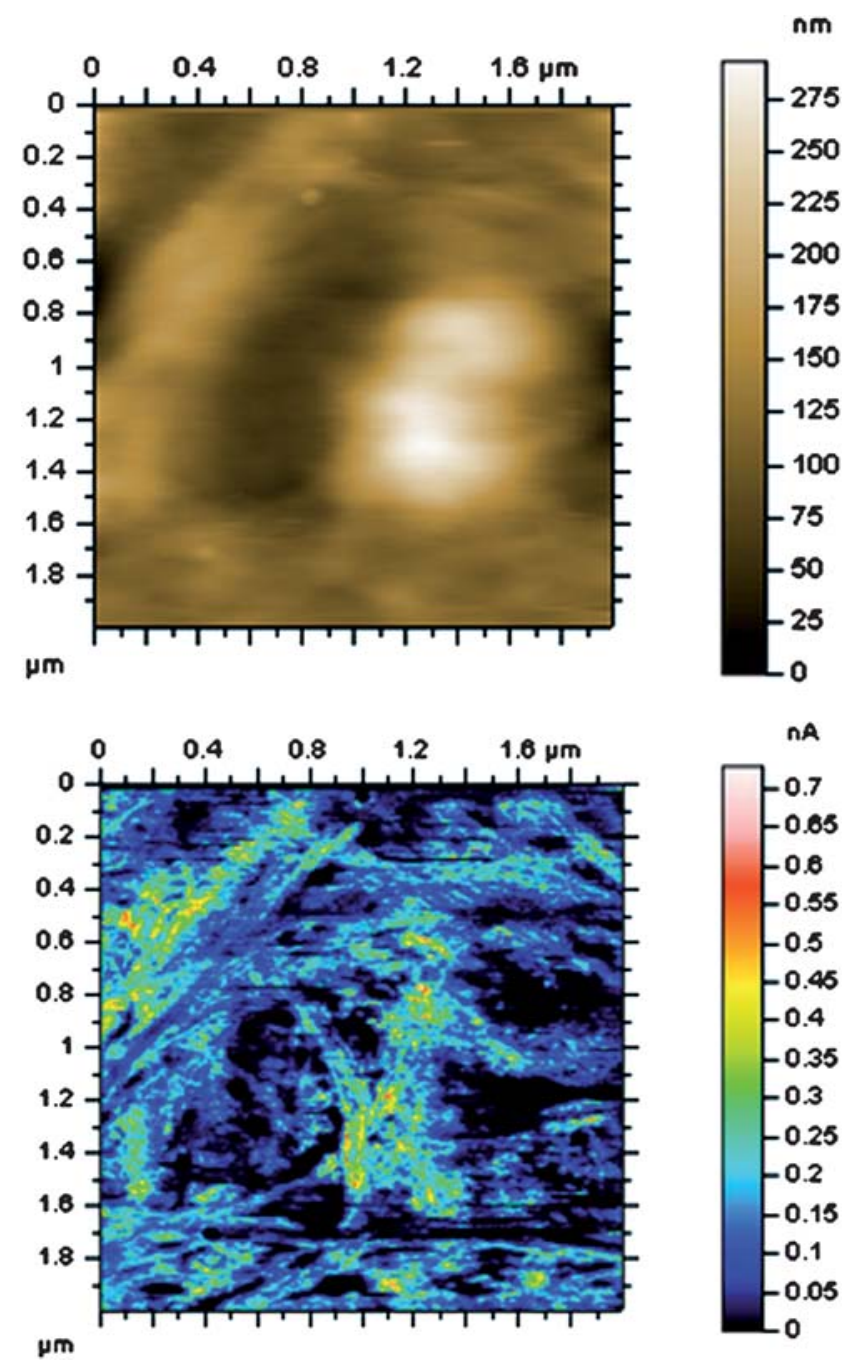

Fig. 11 CS-AFM of the doped xerogel of 1 originating from the THF gel. The top image shows the topographic signal and the lower one the current map (bias $=1 \mathrm{~V}$ ) corresponding to the same region.

at high potential. The doped xerogel prepared from THF has a completely different morphology to the other samples, and it is therefore not surprising, perhaps, that the spectroscopy curve of this sample shows a very different Schottky-type response, which corresponds to semi-conducting type material in bulk conductivity measurements. ${ }^{24}$ In any case, and despite the apparent good connectivity between the fibres, the tape morphology does not seem the best for conductivity in these systems. The fibrous morphologies exhibit much higher transport of charge.

\section{Conclusions}

The multifunctional molecule reported in this paper is an interesting building block, as we have shown that it forms varied selfassembled nanostructures which can be reached through choice of the solvent and the medium (solution or gel) from which it is processed. The main non-covalent force driving its assembly seems to be hydrogen bonding, although NMR experiments indicate that $\pi$-stacking is also evident in the pyrene portion of the molecules. 
(a)
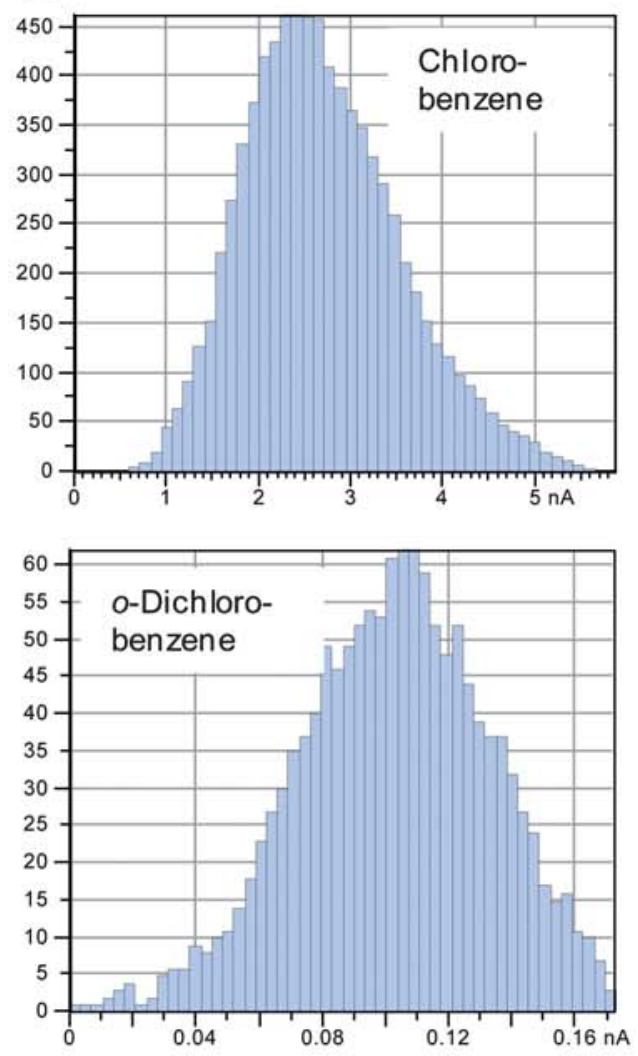

(b)
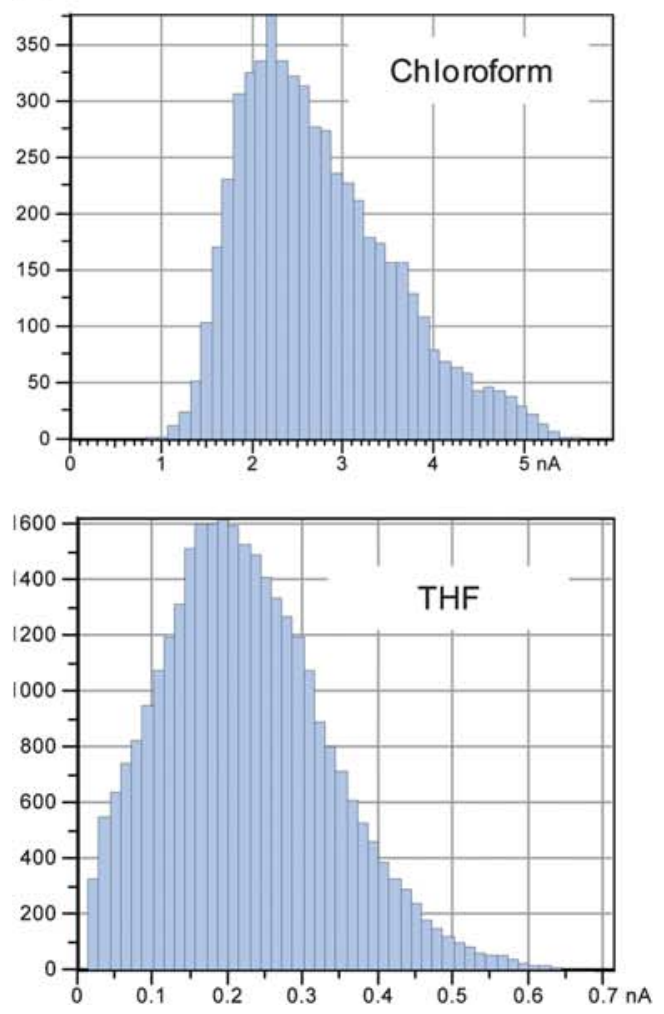

Fig. 12 Histograms indicating the distribution of currents measured through xerogel samples prepared from different solvents.
Current sensing atomic force microscopy shows that doping of the materials results in conductors. Therefore, the TTF units must also be in a stacked arrangement. The solvent used for the processing of the material through the gel state plays an absolutely crucial role in the properties of the material after doping. Well interconnected narrow fibres afford very good transport properties when the material is prepared from chlorobenzene or chloroform. However, very long fibres with less linking between them give a larger resistance in the material.

The unique structure of gelator 1 opens up very interesting perspectives regarding stimuli-responsive gels since bisamides are a well-known class of anion receptors and pyrene emission has been proven to be controlled in TTF-pyrene associations through redox processes.

\section{Experimental section}

\section{General details}

The starting materials were purchased commercially and were used without further purification. Thin-layer chromatography (TLC) was performed on aluminium plates coated with Merck Silica gel 60 F254. Developed plates were air-dried and scrutinized under a UV lamp. Silica gel 60 (35-70 mesh, SDS) was used for column chromatography. ${ }^{1} \mathrm{H}$ and ${ }^{13} \mathrm{C}$ NMR spectra were recorded using the deuterated solvent as an internal reference on a BRUKER Advance DRX 500 spectrometer. Coupling constants are in Hertz.

\section{Synthesis}

2,3-Bis $[N$-(1-pyrenylmethyl)aminocarbonylmethylsulfanyl]tetrathiafulvalene 1. All solutions are previously degassed by bubbling nitrogen through them for $30 \mathrm{~min}$. Caesium hydroxide monohydrate $(451 \mathrm{mg}, 2.7 \mathrm{mmol}, 2.2 \mathrm{eq}$.) in methanol $(7 \mathrm{~mL})$ was added to a solution of TTF $2(815 \mathrm{mg}$, $1.22 \mathrm{mmol}$ ) dissolved in a minimum amount of DMF. After addition, the reaction mixture turned rapidly red and was kept stirring for $30 \mathrm{~min}$. Afterwards, a solution of compound 3 (751 mg, $2.44 \mathrm{mmol}, 2$ eq.) in DMF (30 mL) was slowly added. Stirring was maintained for $24 \mathrm{~h}$ and compound $\mathbf{1}$ was isolated by filtration as an orange solid. The latter was successively washed with water $(200 \mathrm{~mL})$, methanol $(100 \mathrm{~mL})$, diethyl ether $(100 \mathrm{~mL})$ and pentane $(100 \mathrm{~mL})$ to give the analytically pure derivative 1 ( $1 \mathrm{~g}, 74 \%)$.

M.p. $180{ }^{\circ} \mathrm{C}$; FT-IR; $\nu_{\max } / \mathrm{cm}^{-1} 3290(\mathrm{~N}-\mathrm{H}), 1636(\mathrm{C}=\mathrm{O})$, 1548 (-CONH-); ${ }^{1} \mathrm{H}$ NMR (500 MHz, $\left.\mathrm{CDCl}_{3}\right): 7.53(2 \mathrm{H}, \mathrm{d}, J=$ $8.1 \mathrm{~Hz}$, pyrene), $7.45(2 \mathrm{H}, \mathrm{d}, J=8.0 \mathrm{~Hz}$, pyrene), $7.91(\mathrm{~m}, 14 \mathrm{H}$, pyrene), $7.56(2 \mathrm{H}, \mathrm{d}, J=7.7 \mathrm{~Hz}$, pyrene $), 6.54(2 \mathrm{H}, \mathrm{t}, J=5.3 \mathrm{~Hz}$, -NH-), $4.81\left(4 \mathrm{H}, \mathrm{d}, J=5.3 \mathrm{~Hz},-\mathbf{N H}-\mathbf{C H}_{2^{-}}\right), 3.18(4 \mathrm{H}, \mathrm{s}$, $\left.-\mathrm{SCH}_{2} \mathrm{CONH}-\right), 2.78\left(4 \mathrm{H}, \mathrm{t}, J=7.3 \mathrm{~Hz},-\mathrm{SCH}_{2} \mathrm{CH}_{2}-\right), 1.58(4 \mathrm{H}$, $\left.\mathrm{m},-\mathrm{SCH}_{2} \mathbf{C H}_{2^{-}}\right), 1.32\left(4 \mathrm{H}, \mathrm{m}, J=7.1 \mathrm{~Hz},-\mathrm{SCH}_{2} \mathrm{CH}_{2} \mathbf{C H}_{2^{-}}\right), 1.21$ $\left(8 \mathrm{H}, \mathrm{m},-\mathrm{CH}_{2}\left(\mathbf{C H}_{2}\right)_{4} \mathrm{CH}_{3}\right), 0.83\left(6 \mathrm{H}, \mathrm{t}, J=7.2 \mathrm{~Hz},-\mathbf{C H}_{3}\right) ;{ }^{13} \mathrm{C}$ NMR (125 MHz, THF-d $)$ : $167.6(\mathbf{C}=\mathbf{O}), 133.2,132.5,132.0$, $131.9,129.9,129.5,129.0,128.7,128.3,128.0,127.9,126.8,126.1$, 126.0, 125.9, 125.8, 125.6, 124.1 (Pyrene and TTF external $\mathbf{C}=\mathbf{C}$ ), 111.4, 110.6 (TTF internal $\mathbf{C}=\mathbf{C}$ ), 42.7, 39.5, 37.1, 32.9, 30.9, 30.3, 30.1, 29.5, 23.6, 14.5; HR-MS m/z: $\left(\mathrm{M}^{+\bullet}\right)$ calculated: 1098.2577, detected: 1098.2579. 


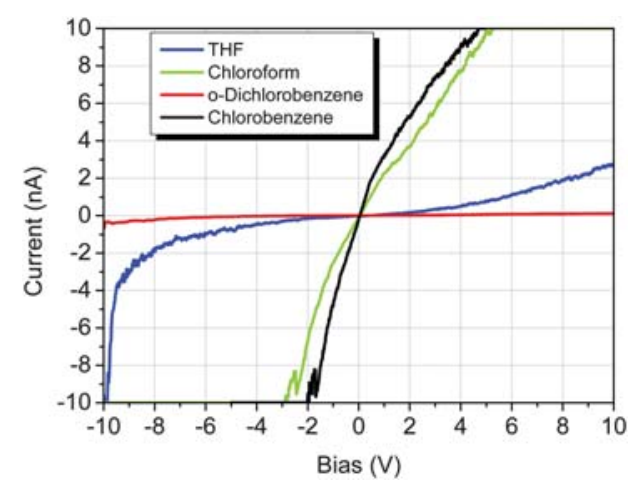

Fig. 13 Representative $I-V$ sweeps recorded during the CS-AFM experiments on the doped xerogels from the different solvents.

2,3-Bis(2-cyanoethylsulfanyl)-6,7-bis(octylsulfanyl)tetrathiafulvalene 2. A mixture of 4,5-bis(octylsulfanyl)-1,3-dithiole-2thione (1.268 g, $3 \mathrm{mmol})$ and 4,5-bis(2-cyanoethyl-sulfanyl)1,3-dithiole-2-one ( $865 \mathrm{mg}, 3 \mathrm{mmol})$ was refluxed in toluene $(18 \mathrm{~mL})$ until complete solubilization. Trimethylphosphite $(6 \mathrm{~mL})$ was added in one portion and refluxed for four hours. After cooling, solvents were concentrated in vacuo and the resulting slurry was chromatographed on silica gel (eluent: $\left.\mathrm{CH}_{2} \mathrm{Cl}_{2}\right)$ affording the desired compound $2(1 \mathrm{~g}, 50 \%)$.

M.p. $110{ }^{\circ} \mathrm{C},{ }^{1} \mathrm{H}$ NMR $\left(500 \mathrm{MHz}\right.$, acetone- $\left.\mathrm{d}_{6}\right): 3.25(4 \mathrm{H}, \mathrm{t}$, $\left.J=6.9 \mathrm{~Hz},-\mathbf{C H}_{2}-\mathrm{CN}\right), 2.95\left(4 \mathrm{H}, \mathrm{t}, J=6.9 \mathrm{~Hz},-\mathrm{SCH}_{2} \mathrm{CH}_{2} \mathrm{CN}\right)$, $2.90\left(4 \mathrm{H}, \mathrm{t}, J=7.3 \mathrm{~Hz},-\mathrm{SCH}_{2} \mathrm{CH}_{2} \mathrm{CH}_{2}-\right), 1.66(4 \mathrm{H}, \mathrm{m}$, $\left.\mathrm{SCH}_{2} \mathbf{C H}_{2} \mathrm{CH}_{2}-\right), 1.46\left(4 \mathrm{H}, \mathrm{m}, \mathrm{SCH}_{2} \mathrm{CH}_{2} \mathbf{C H}_{2}-\right), 1.31(16 \mathrm{H}, \mathrm{m}$, $\left.-\left(\mathbf{C H}_{2}\right)_{4} \mathrm{CH}_{3}\right), 0.87\left(6 \mathrm{H}, \mathrm{t}, J=7.1 \mathrm{~Hz},-\mathbf{C H}_{3}\right) ;{ }^{13} \mathrm{C} \mathrm{NMR}$ $\left(125 \mathrm{MHz}\right.$, acetone- $\left.\mathrm{d}_{6}\right)$ 127.9, $127.8($ TTF external $\mathbf{C}=\mathbf{C}), 117.4$ (-CN), 114.7, 106.3 (TTF internal C=C), 36.3, 31.8, 31.2, 29.7, 29.1, 29.0, 28.5, 22.6, 18.9, 14.1; HR-MS $m / z:\left(\mathrm{M}^{+\bullet}\right)$, calculated: 662.1114, detected: 662.1112 .

Cyclic voltammetry measurements. Cyclic voltammograms were acquired using a three-electrode cell equipped with a platinum working electrode $(\varnothing=2 \mathrm{~mm})$, a platinum wire as a counter-electrode and an $\mathrm{Ag} / \mathrm{Ag}^{+}$pseudoreference. Potentials were subsequently adjusted using ferrocene as an internal reference. These measurements were performed on an EGG PAR $273 \mathrm{~A}$ potentiostat with positive feedback compensation.

SEM measurements. SEM images were acquired by scanning electron microscope (SEM) HITACHI S-3000N on a Hitachi S-570 system operating at $20 \mathrm{kV}$. To facilitate SEM measurements of the texture, experiments were carried out under partial vacuum with a low pressure of water. The solution samples were dropped onto glass and allowed to dry, and the gel sample was deposited as such and then dried.

TEM measurements. TEM images were acquired with a Jeol JEM 2011 microscope on unstained samples. Holey carbon grids were used, where samples were deposited as a hot drop of solution and allowed to dry using a vacuum pump when necessary.

\section{AFM experiments}

Solutions of $\mathbf{1}$ in the different solvents were prepared by gentle warming prior to deposition of a drop on freshly cleaved graphite
(ZYB grade). The atomic force microscopy (AFM) images were recorded on an Agilent Technologies 5100 AFM. The acoustic mode was used with resonance frequencies of the silicon tips (Nanosensors, FM type force constant $1.2-3.5 \mathrm{~N} \mathrm{~m}^{-1}$ and diameter $5 \mathrm{~nm}$ ) of around $60-70 \mathrm{kHz}$. All the images were recorded under atmospheric conditions. Current images of the doped samples on the graphite substrates were obtained by using the same AFM system. Contact working mode with a bias voltage applied to the sample while scanning, with a grounded conducting Pt-Ir coated silicon tip (force constant around $1.2 \mathrm{~N}$ $\mathrm{m}^{-1}$ ), is necessary in order to perform such experiments. Electrical contact to the sample was made using a stainless steel clamp pressed onto the surface of the doped xerogel on highly ordered pyrolitic graphite (XYB grade) substrate. The images were processed using Mountains software from Digital Surf.

\section{Acknowledgements}

This work was in part supported by the program ANR PNANO (TTF-Based Nanomat), the Generalitat de Catalunya (2009 SGR 158), and the COST D31 Action (Organizing Non-Covalent Chemical Systems with Selected Functions).

\section{References}

1 For reviews see: (a) J. A. A. W. Elemans, A. E. Rowan and R. J. M. Nolte, J. Mater. Chem., 2003, 13, 2661; (b) F. J. M. Hoeben, P. Jonkheijm, E. W. Meijer and A. P. H. J. Schenning, Chem. Rev., 2005, 105, 1491; (c) D. L. Long, E. Burkholder and L. Cronin, Chem. Soc. Rev., 2007, 36, 105; For more recent examples, see: $(d)$ G. F. Lu, X. M. Zhang, X. Cai and J. Z. Jiang, J. Mater. Chem., 2009, 19, 2417; (e) V. Stepanenko, M. Stocker, P. Muller, M. Buchner and F. Würthner, J. Mater. Chem., 2009, 19, 6816; (f) S. Yagai, S. Kubota, H. Saito, K. Unoike, T. Karatsu, A. Kitamura, A. Ajayaghosh, M. Kanesato and Y. Kikkawa, J. Am. Chem. Soc., 2009, 131, 5408; $(g)$ N. Crivillers, S. Furukawa, A. Minoia, A. Ver Heyen, M. MasTorrent, C. Sporer, M. Linares, A. Volodin, C. Van Haesendonck, M. Van der Auweraer, R. Lazzaroni, S. De Feyter, J. Veciana and C. Rovira, J. Am. Chem. Soc., 2009, 131, 6246; (h) A. Carlsen and S. Lecommandoux, Curr. Opin. Colloid Interface Sci., 2009, 14, 329; (i) E. Beltrán, E. Cavero, J. Barbera, J. L. Serrano, A. Elduque and R. Giménez, Chem.-Eur. J., 2009, 15, 9017; (j) M. Hasegawa and M. Iyoda, Chem. Soc. Rev., 2010, 39, 2420.

2 (a) C. Park, J. Yoon and E. L. Thomas, Polymer, 2003, 44, 6725; (b) A. H. Flood, R. J. A. Ramirez, W. Q. Deng, R. P. Muller, W. A. GoddardIII and J. F. Stoddart, Aust. J. Chem., 2004, 57, 301; (c) M. Cavallini, M. Facchini, M. Massi and F. Biscarini, Synth. Met., 2004, 146, 283; (d) A. P. H. J. Schenning and E. W. Meijer, Chem. Commun., 2005, 3245; (e) M. Haga, K. Kobayashi and K. Terada, Coord. Chem. Rev., 2007, 251, 2688; (f) R. Madueno, M. T. Raisanen, C. Silien and M. Buck, Nature, 2008, 454, 618; (g) J. H. Liu, J. H. Zou and L. Zhai, Macromol. Rapid Commun., 2009, 30, 1387.

3 (a) J. Puigmartí-Luis, A. Minoia, H. Uji-i, C. Rovira, J. Cornil, S. De Feyter, R. Lazzaroni and D. B. Amabilino, J. Am. Chem. Soc., 2006, 128, 12602; (b) S. Srinivasan, V. K. Praveen, R. Philip and A. Ajayaghosh, Angew. Chem., Int. Ed., 2008, 47, 5750; (c) H. Imahori and T. Umeyama, J. Phys. Chem. C, 2009, 113, 9029; (d) S. Lena, S. Masiero, S. Pieraccini and G. P. Spada, Chem-Eur. J., 2009, 15, 7792; (e) Q. Shen, X. F. Guo, M. L. Steigerwald and C. Nuckolls, Chem.-Asian J., 2010, 5, 1040; (f) F. Tancini, D. Genovese, M. Montalti, L. Cristofolini, L. Nasi, L. Prodi and E. Dalcanale, J. Am. Chem. Soc., 2010, 132, 4781-4789; (g) K. Ariga, X. L. Hu, S. Mandal and J. P. Hill, Nanoscale, 2010, 2, 198. 4 For a review: (a) F. J. M. Hoeben, P. Jonkheijm, E. W. Meijer and A. Schenning, Chem. Rev., 2005, 105, 1491; For recent examples: (b) S. Yagai, Y. Monma, N. Kawauchi, T. Karatsu and A. Kitamura, Org. Lett., 2007, 9, 1137; (c) S. Ghosh, X.-Q. Li, V. Stepanenko 
and F. Würthner, Chem.-Eur. J., 2008, 14, 11343; (d) T. Seki, S. Yagai, T. Karatsu and A. Kitamura, Chem. Lett., 2008, 37, 764; (e) Y. Hirai, S. S. Babu, V. K. Praveen, T. Yasuda, A. Ajayaghosh and T. Kato, Adv. Mater., 2009, 21, 4029; ( $f$ ) D. Jang, H. Y. Lee, M. Park, S. R. Nam and J.-I. Hong, Chem-_Eur. J., 2010, 16, 4836.

5 (a) J. Puigmartí-Luis, A. Minoia, A. Pérez del Pino, G. Ujaque, C. Rovira, A. Lledós, R. Lazzaroni and D. B. Amabilino, Chem.Eur. J., 2006, 12, 9161; (b) A. Ajayaghosh, P. Chithra and R. Varghese, Angew. Chem., Int. Ed., 2007, 46, 230; (c) L. Jiang, Y. Fu, H. Li and W. Hu, J. Am. Chem. Soc., 2008, 130, 3937; (d) E. Gomar-Nadal, J. Puigmartí-Luis and D. B. Amabilino, Chem. Soc. Rev., 2008, 37, 490; (e) J.-H. Ryu, D.-J. Hong and M. Lee, Chem. Commun., 2008, 1043; $(f)$ E. Torres, J. Puigmartí-Luis, Á. Pérez del Pino, R. M. Ortuño and D. B. Amabilino, Org. Biomol. Chem., 2010, 8, 1661; (g) G. De Luca, E. Treossi, A. Liscio, J. M. Mativetsky, M. Jeffrey, L. M. Scolaro, V. Palermo and P. Samori, J. Mater. Chem., 2010, 20, 2493; (h) N. Kumaran, P. A. Veneman, B. A. Minch, A. Mudalige, J. E. Pemberton, D. F. O'Brien and N. R. Armstrong, Chem. Mater., 2010, 22, 2491.

6 (a) A. R. Hirst, B. Escuder, J. F. Miravet and D. K. Smith, Angew. Chem., Int. Ed., 2008, 47, 8002; (b) A. Ajayaghosh, V. K. Praveen and C. Vijayakumar, Chem. Soc. Rev., 2008, 37, 109; (c) S. Banerjee, R. K. Das and U. Maitra, J. Mater. Chem., 2009, 19, 6649; (d) D. B. Amabilino and J. Puigmartí-Luis, Soft Matter, 2010, 6, 1605 .

7 (a) J. Puigmartí-Luis, V. Laukhin, A. Pérez del Pino, J. VidalGancedo, C. Rovira, E. Laukhina and D. B. Amabilino, Angew. Chem., Int. Ed., 2007, 46, 238; (b) J. Puigmartí-Luis, A. Pérez del Pino, E. Laukhina, J. Esquena, V. Laukhin, C. Rovira, J. VidalGancedo, A. G. Kanaras, R. J. Nichols, M. Brust and D. B. Amabilino, Angew. Chem., Int. Ed., 2008, 47, 1861; (c) S. Prasanthkumar, A. Saeki, S. Seki and A. Ajayaghosh, J. Am. Chem. Soc., 2010, 132, 8866.

8 For recent examples, see: (a) C. Wang, Q. Chen, F. Sun, D. Zhang, G. Zhang, Y. Huang, R. Zhao and D. Zhu, J. Am. Chem. Soc., 2010, 132, 3092; (b) Y. Tanaka, T. Ishisaka, A. Inagaki, T. Koike, C. Lapinte and M. Akita, Chem.-Eur. J., 2010, 16, 4762; (c) J. Kärnbratt, M. Hammarson, S. Li, H. L. Anderson, B. Albinsson and J. Andréasson, Angew. Chem., Int. Ed., 2010, 49, 1854; (d) K. Motoyama, T. Koike and M. Akita, Chem. Commun., 2008, 5812; (e) T. Muraoka, K. Kinbara and T. Aida, Nature, 2006, 440, 512.

9 (a) J. Sly, P. Kasák, E. Gomar-Nadal, C. Rovira, L. Górriz, P. Thordarson, D. B. Amabilino, A. E. Rowan and R. J. M. Nolte, Chem. Commun., 2005, 1255; (b) B. Ballesteros, S. Campidelli, G. de la Torre, C. Ehli, D. M. Guldi, M. Prato and T. Torres, Chem. Commun., 2007, 2950; (c) C. Ehli, D. M. Guldi, M. Á. Herranz, N. Martín, S. Campidelli and M. Prato, J. Mater. Chem., 2008, 18, 1498; (d) E. Schwartz, S. Le Gac, J. J. L. M. Cornelissen, R. J. M. Nolte and A. E. Rowan, Chem. Soc. Rev., 2010, 39, 1576; (e) C. C. You, C. Hippius, M. Grüne and F. Würthner, Chem.Eur. J., 2006, 12, 7510 .

10 (a) M. Iyoda, M. Hasegawa and H. Enozawa, Chem. Lett., 2007, 36, 1402; (b) D. Canevet, M. Sallé, G. Zhang, D. Zhang and D. Zhu, Chem. Commun., 2009, 2245; (c) Y. Geng, X. J. Wang, B. Chen, H. Xue, Y. P. Zhao, S. Lee, C. H. Tung and L. Z. Wu, Chem.Eur. J., 2009, 15, 5124; (d) N. Martín and J. L. Segura, Angew. Chem., Int. Ed., 2001, 40, 1372.

11 J. B. Birks, Photophysics of aromatic molecules, Wiley-Interscience, London, New York, 1970.

12 (a) X. Xiao, W. Xu, D. Zhang, H. Xu, L. Liu and D. Zhu, New J. Chem., 2005, 29, 1291; (b) L. Liu, G. Zhang, W. Tan, D. Zhang and D. Zhu, Chem. Phys. Lett., 2008, 465, 230; (c) A. S. Abreu, E. M. S. Castanheira, P. M. T. Ferreira, L. S. Monteiro, G. Pereira and M.-J. R. P. Queiroz, Eur. J. Org. Chem., 2008, 5697; (d) M. Hissler, A. Harriman, A. Khatyr and R. Ziessel, Chem.-Eur. J., 1999, 5, 3366 .

13 (a) M. Jørgensen, K. Bechgaard, T. Bjørnholm, O. Sommer-Larsen, L. G. Hansen and K. Schaumburg, J. Org. Chem., 1994, 59, 5877; (b) T. Kitamura, S. Nakaso, N. Mizoshita, Y. Tochigi, T. Shimomura, M. Moriyama, K. Ito and T. Kato, J. Am. Chem. Soc., 2005, 127, 14769; (c) T. Kitahara, M. Shirakawa, S. -i. Kawano, U. Beginn, N. Fujita and S. Shinkai, J. Am. Chem. Soc., 2005, 127, 14980; (d)
C. Wang, D. Zhang and D. Zhu, J. Am. Chem. Soc., 2005, 127, 16372; (e) T. Akutagawa, K. Kakiuchi, T. Hasegawa, S.-i. Noro, T. Nakamura, H. Hasegawa, S. Mashiko and J. Becher, Angew. Chem., Int. Ed., 2005, 44, 7283; (f) Y. Kobayashi, M. Hasegawa, H. Enozawa and M. Iyoda, Chem. Lett., 2007, 36, 720; $(g)$ H. Enozawa, Y. Honna and M. Iyoda, Chem. Lett., 2007, 36, 1434; (h) I. Danila, F. Riobé, J. Puigmartí-Luis, Á. Pérez del Pino, J. D. Wallis, D. B. Amabilino and N. Avarvari, J. Mater. Chem., 2009, 19, 4495.

14 (a) U. Maitra, P. V. Kumar, N. Chandra, L. J. D'Souza, M. D. Prasanna and A. R. Raju, Chem. Commun., 1999, 595; (b) T. Sagawa, S. Fukugawa, T. Yamada and H. Ihara, Langmuir, 2002, 18, 7223; (c) P. Babu, N. M. Sangeetha, P. Vijaykumar, U. Maitra, K. Rissanen and A. R. Raju, Chem.-Eur. J., 2003, 9, 1922; (d) H. Ihara, T. Yamada, M. Nishihara, T. Sakurai, M. Takafuji, H. Hachisako and T. Sagawa, J. Mol. Liq., 2004, 111, 73; (e) C. Wang, Z. Wang, D. Zhang and D. Zhu, Chem. Phys. Lett., 2006, 428, 130; $(f)$ Y. Kamikawa and T. Kato, Langmuir, 2007, 23, 274; (g) W. Cai, G.-T. Wang, P. Du, R.-X. Wang, X.K. Jiang and Z.-T. Li, J. Am. Chem. Soc., 2008, 130, 13450; $(h)$ A. Hahma, S. Bhat, K. Leivo, J. Linnanto, M. Lahtinen and K. Rissanen, New J. Chem., 2008, 32, 1438; (i) S. Diring, F. Camerel, B. Donnio, T. Dintzer, S. Toffanin, R. Capelli, M. Muccini and R. Ziessel, J. Am. Chem. Soc., 2009, 131, 18177.

15 N. J. van der Veen, S. Flink, M. A. Deij, R. J. M. Egberink, F. C. J. M. van Veggel and D. N. Reinhoudt, J. Am. Chem. Soc., 2000, 122, 6112.

16 (a) K. Kawai, K. Miyamoto, S. Tojo and T. Majima, J. Am. Chem. Soc., 2003, 125, 912; (b) K. Kawai, H. Yoshida, T. Takada, S. Tojo and T. Majima, J. Phys. Chem. B, 2004, 108, 13547; (c) K. Kawai, T. Kimura, H. Yoshida, A. Sugimoto, S. Tojo, M. Fujitsuka and T. Majima, Bull. Chem. Soc. Jpn., 2006, 79, 312.

17 (a) A. Knorr and J. Daub, Angew. Chem., Int. Ed. Engl., 1996, 34, 2664; (b) T. Gareis, O. Köthe and J. Daub, Eur. J. Org. Chem., $1998,1549$.

18 J. Puigmartí-Luis, Á. Pérez del Pino, V. Laukhin, L. N. Feldborg, C. Rovira, E. Laukhina and D. B. Amabilino, J. Mater. Chem., 2010, 20, 466.

19 (a) Q. N. Pham, N. Brosse, C. Frochot, D. Dumas, A. Hocquet and B. Jamart-Grégoire, New J. Chem., 2008, 32, 1131; (b) M. O. M. Piepenbrock, G. O. Lloyd, N. Clarke and J. W. Steed, Chem. Commun., 2008, 2644.

20 (a) A. R. Hirst and D. K. Smith, Langmuir, 2004, 20, 10851; (b) G. Zhu and J. S. Dordick, Chem. Mater., 2006, 18, 5988; (c) M. Bielejewski, A. Łapiński, R. Luboradzki and J. Tritt-Goc, Langmuir, 2009, 25, 8274; (d) M. A. Rogers and A. G. Marangoni, Langmuir, 2009, 25, 8556.

21 (a) Q. Guo, J. Yin, F. Yin, R. E. Palmer, N. Bampos and J. K. M. Sanders, J. Phys.: Condens. Matter, 2003, 15, S3127; (b) V. Palermo, M. Palma, Z. Tomovic, M. D. Watson, K. Müllen and P. Samorì, Synth. Met., 2004, 147, 117; (c) G. Ridolfi, L. Favaretto, G. Barbarella, P. Samorì and N. Camaioni, J. Mater. Chem., 2005, 15, 1704; (d) M. Kastler, W. Pisula, D. Wasserfallen, T. Pakula and K. Müllen, J. Am. Chem. Soc., 2005, 127, 4286; (e) A. Arena, S. Patane, G. Saitta and A. Bonavita, Mater. Lett., 2006, 60, 2171; (f) J. Y. Wang, J. Yan, Z. D. Li, J. M. Han, Y. G. Ma, J. Bian and J. Pei, Chem.-Eur. J., 2008, 14, 7760; (g) P. Iavicoli, M. SimónSorbed and D. B. Amabilino, New J. Chem., 2009, 33, 358.

22 (a) R. van Hameren, P. Schön, A. M. van Buul, J. Hoogboom, S. V. Lazarenko, J. W. Gerritsen, H. Engelkamp, P. C. M. Christianen, H. A. Heus, J. C. Maan, T. Rasing, S. Speller, A. E. Rowan, J. A. A. W. Elemans and R. J. M. Nolte, Science, 2006, 314, 1433; (b) R. van Hameren, A. M. van Buul, M. A. Castriciano, V. Villari, N. Micali, P. Schön, S. Speller, L. Monsù Scolaro, A. E. Rowan, J. A. A. W. Elemans and R. J. M. Nolte, Nano Lett., 2008, 8, 253.

23 (a) J. B. Torrance, B. A. Scott, B. Welber, F. B. Kaufman and P. E. Seiden, Phys. Rev. B: Condens. Matter, 1979, 19, 730; (b) R. Bozio, I. Zanon, A. Girlando and C. Pecile, J. Chem. Phys., 1979, 71, 2282.

24 J. Puigmartí-Luis, E. E. Laukhina, V. N. Laukhin, Á. Pérez del Pino, N. Mestres, J. Vidal-Gancedo, C. Rovira and D. B. Amabilino, $A d v$. Funct. Mater., 2009, 19, 934. 